\title{
Transjugular intrahepatic portosystemic shunt before abdominal surgery in cirrhotic patients: A retrospective, comparative study
}

\author{
Evelyne Vinet $M D^{1}$, Pierre Perreault $M D^{2}$, Louis Bouchard $M D^{2}$, Denis Bernard $M D^{3}$, \\ Ramses Wassef $M D^{3}$, Carole Richard $M D^{3}$, Richard Létourneau $M^{4}$, Gilles Pomier-Layrargues $M^{1}$
}

\begin{abstract}
E Vinet, P Perreault, L Bouchard, et al. Transjugular intrahepatic portosystemic shunt before abdominal surgery in cirrhotic patients: A retrospective, comparative study. Can J Gastroenterol 2006;20(6):401-404.
\end{abstract}

\begin{abstract}
Surgery in cirrhotic patients is associated with high morbidity and mortality related to portal hypertension and liver insufficiency. Therefore, preoperative portal decompression is a logical approach to facilitate abdominal surgery and hopefully to improve postoperative survival. The present study evaluated the clinical outcomes of 18 patients (mean age 58 years) with cirrhosis (seven alcoholics and 11 nonalcoholics) who underwent transjugular intrahepatic portosystemic shunt (TIPS) placement before antrectomy $(n=5)$, colectomy $(n=10)$, small-bowel resection $(n=1)$, pancreatectomy $(n=1)$ and nephrectomy $(n=1)$. TIPS was performed a mean $( \pm S D)$ of $72 \pm 21$ days before surgery and induced a marked mean decrease in portohepatic gradient from $21.4 \pm 3.9 \mathrm{mmHg}$ to $8.4 \pm 3.4 \mathrm{mmHg}$. Cirrhotic patients $(n=17)$ who underwent elective abdominal surgery without preoperative TIPS placement were used as the control group. Both groups were matched for age, etiology of cirrhosis, indications for surgery, type of surgery and coagulation parameters. The mean Pugh score was significantly higher in the TIPS group (7.7 versus 6.2). No significant differences were observed for operative blood loss, postoperative complications, duration of hospitalization and one-month $(83 \%$ versus $88 \%$ ) or one-year (54\% versus $63 \%$ ) cumulative survival rate. Analysis using the Cox proportional hazards model showed that neither TIPS placement nor preoperative Pugh score were independent predictors for survival. The present study suggests that preoperative TIPS placement does not improve postoperative evolution after abdominal surgery in cirrhotic patients with good or moderately impaired liver function.
\end{abstract}

Key Words: Abdominal surgery; Liver cirrhosis; Liver failure; Portal hypertension; Transjugular intrahepatic portosystemic shunt

bdominal surgery is occasionally needed in cirrhotic
patients and is associated with high morbidity and mortality
rates (1-3). It has been suggested that the main determinant of
short- and long-term survival is the degree of liver failure, as
evaluated by the presence of ascites, low serum albumin level
and coagulation disorders. In addition, the degree of portal
hypertension may be an independent predictor for operative
bleeding, postoperative ascites leakage or variceal rupture; this

\section{Une dérivation transjugulaire intrahépatique portosystémique avant une intervention abdominale chez des patients cirrhotiques : Une étude rétrospective comparative}

\begin{abstract}
Les interventions chirurgicales chez les patients cirrhotiques s'associent à des taux élevés de morbidité et de mortalité reliés à l'hypertension portale et à l'insuffisance hépatique. Par conséquent, la décompression portale préopératoire constitue une démarche logique afin de faciliter une opération abdominale et, si tout va bien, d'améliorer la survie postopératoire. La présente étude a permis d'évaluer les issues cliniques de 18 patients (âge moyen de 58 ans) cirrhotiques (sept alcooliques et 11 nonalcooliques) qui avaient subi une dérivation transjugulaire intrahépatique portosystémique (DTIP) avant une antrectomie $(n=5)$, une colectomie $(n=10)$, une résection de l'intestin grêle $(n=1)$, une pancréatectomie $(n=1)$ et une néphrectomie $(\mathrm{n}=1)$. La DTIP a été exécutée en moyenne $( \pm$ ÉT) $72 \pm 21$ jours avant l'opération et a induit une diminution moyenne marquée du gradient portohépatique, qui est passé de $21,4 \pm 3,9 \mathrm{mmHg}$ à $8,4 \pm 3,4 \mathrm{mmHg}$. Des patients cirrhotiques $(\mathrm{n}=17)$ qui avaient subi une intervention abdominale non urgente sans DTIP préopératoire ont servi de groupe témoin. Les deux groupes étaient appariés selon l'âge, l'étiologie de la cirrhose, les indications d'opérer, le type d'opération et les paramètres de coagulation. L'indice de Pugh moyen étaient considérablement plus élevé au sein du groupe ayant subi la DTIP $(7,7$ par rapport à $6,2)$. On n'a remarqué aucune différence significative pour ce qui est de la perte de sang opératoire, des complications postopératoires, de la durée de l'hospitalisation et du taux de survie cumulatif au bout d'un mois $(83 \%$ par rapport à $88 \%$ ) ou d'un an (54\% par rapport à $63 \%)$. L'analyse au moyen du modèle des hasards proportionnels de Cox a démontré que ni la DTIP ni l'indice de Pugh préopératoire n'étaient des prédicteurs indépendants de survie. D'après la présente étude, la DTIP préopératoire n'améliore pas l'évolution postopératoire après une intervention abdominale chez des patients cirrhotiques dont la fonction hépatique est bonne ou modérément atteinte.
\end{abstract}

may also influence survival. Transjugular intrahepatic portosystemic shunt (TIPS) placement is much less invasive than surgical shunts and can be performed in patients with a significant degree of liver insufficiency (4). Therefore, it has been suggested that preoperative TIPS placement may improve the prognosis of cirrhotic patients, submitted to abdominal surgery (5). However, this statement relies on a very limited number of patients and comparison with

${ }^{1}$ Liver Unit; ${ }^{2}$ Radiology Department; ${ }^{3}$ Digestive Surgery Unit; ${ }^{4}$ Hepatobiliary Surgery Unit, Hopital Saint-Luc, Centre Hospitalier de l'Universite de Montreal, Montreal, Quebec

Correspondence: Dr Gilles Pomier-Layrargues, 264 East Rene-Levesque Boulevard, Montreal, Quebec H2X 1 P1.

Telephone 514-890-8000 ext 35718,fax 514-412-7314, e-mail hepato.saint-luc@sympatico.ca

Received for publication January 24, 2006. Accepted January 24, 2006 


\section{TABLE 1}

Patients characteristics before surgery

\begin{tabular}{|c|c|c|c|}
\hline Parameter & Group 1 (n=18) & Group $2(n=17)$ & $\mathbf{P}$ \\
\hline Age $^{*}$, years & $58 \pm 14$ & $62 \pm 12$ & NS \\
\hline Sex (male/female) & $14 / 4$ & $11 / 6$ & NS \\
\hline Alcoholic cirrhosis, $n$ & 7 & 6 & NS \\
\hline Ascites, $n$ & 7 & 5 & NS \\
\hline Previous encephalopathy, $n$ & 3 & 0 & NS \\
\hline Hemoglobin*, g/L & $103 \pm 16$ & $120 \pm 15$ & NS \\
\hline Serum albumin ${ }^{*}, \mathrm{~g} / \mathrm{L}$ & $25.4 \pm 5.3$ & $31.9 \pm 6.9$ & NS \\
\hline Serum bilirubin ${ }^{*}, \mu \mathrm{mol} / \mathrm{L}$ & $31 \pm 21$ & $13 \pm 6$ & NS \\
\hline International normalized ratio* & $1.19 \pm 5.3$ & $1.09 \pm 6.9$ & NS \\
\hline Platelets ${ }^{*}, \times 10^{9} / \mathrm{mL}$ & $123 \pm 54$ & $189 \pm 67$ & NS \\
\hline Pugh score, median (range) & $7.7(6-10)$ & $6.2(5-9)$ & $<0.05$ \\
\hline $\begin{array}{l}\text { Transjugular intrahepatic } \\
\text { portosystemic shunt } \\
\text { velocity }^{*} \mathrm{~cm} / \mathrm{s}\end{array}$ & $52 \pm 10$ & - & - \\
\hline
\end{tabular}

${ }^{*}$ Mean $\pm S D$. NS Not significant

abdominal surgery in cirrhotic patients without preoperative portal decompression is not available.

In the present study, using a retrospective design, we evaluated the postoperative morbidity and mortality rates after major abdominal surgery in cirrhotic patients with or without preoperative TIPS placement.

\section{PATIENTS AND METHODS}

\section{Patient selection}

Between 1992 and 2002, 18 cirrhotic patients received TIPS placement before an elective abdominal operation (group 1).

All cirrhotic patients who underwent an elective abdominal surgery without preoperative TIPS placement during the same period were used as the control group (group 2;n=17). The decision to place a prophylactic TIPS was made by the surgeon in charge of the patient.

\section{TIPS procedure}

TIPS placement was performed as previously reported (6). Briefly the hepatic vein was catheterized using the transjugular approach, and the tract between the portal and hepatic vein was then dilated up to $10 \mathrm{~mm}$ using balloon angioplasty catheters; thereafter, a stent was inserted to create the shunt. Insertion of two or more stents was needed in selected cases because of the length of the parenchymal tract. Shunting was aimed at decreasing the portocaval gradient below $12 \mathrm{mmHg}$, which is the threshold value associated with the risk of variceal bleeding or ascites formation. A $24 \mathrm{~h}$ antibioprophylaxis was provided but no anticoagulation was used. The patency of the shunt was verified using duplex Doppler ultrasonography at $24 \mathrm{~h}$ and then immediately before surgery which was performed a mean $( \pm$ SD) of $72 \pm 21$ days after TIPS placement. This time interval was chosen deliberately to allow for recovery from the transient deterioration in liver function frequently observed after TIPS placement. All patients signed an informed consent form before the TIPS procedure.

\section{End points}

The primary end point was the survival rate. The secondary end points were the amount of operative blood loss, the incidence of postoperative complications (liver failure, encephalopathy,
TABLE 2

Indications and type of abdominal surgery

\begin{tabular}{lcc}
\hline & Group $\mathbf{1}$ (n=18) & Group 2 (n=17) \\
\hline Type of surgery & 10 & 13 \\
Colectomy & 1 & 2 \\
Duodenopancreatectomy & 5 & 1 \\
Gastrectomy & 1 & 1 \\
Nephrectomy & 1 & 0 \\
Small-bowel resection & & \\
Indication for surgery & 8 & 10 \\
Colon cancer & 0 & 1 \\
Colon angiodysplasia & 0 & 1 \\
Bladder cancer with colon involvement & 2 & 1 \\
Ulcerative colitis & 3 & 1 \\
Gastric antral vascular ectasia & 1 & 0 \\
Gastric cancer & 1 & 0 \\
Gastric polyp & 1 & 0 \\
Ampulloma & 1 & 0 \\
Small-bowel stenosis & 0 & 1 \\
Cholangiocarcinoma & 0 & 1 \\
Chronic pancreatitis & 1 & 1 \\
Kidney cancer & &
\end{tabular}

ascitic fluid leak, infections and miscellaneous) and the length of hospitalization following surgery.

\section{Statistics}

Values were expressed as mean \pm SD if they were normally distributed. Otherwise, medians and ranges were provided. Differences between the two study groups were tested using the $\chi^{2}$ exact test or the Wilcoxon rank order test for nonparametric variables and ANOVA for continuous data. The survival rate was calculated according to the Kaplan-Meier method for each group; groups were compared using the log rank test. The prognostic value of the TIPS procedure and of the preoperative Pugh score with respect to survival was assessed in univariate analysis and in multivariate analysis with the Cox proportional hazards model. Results of the statistical tests were considered to be significant at $\mathrm{P}<0.05$.

\section{RESULTS}

Clinical and biochemical characteristics of the patients in group $1(\mathrm{n}=18)$ and group $2(\mathrm{n}=17)$ are summarized in Table 1 . The two groups were matched for age, sex ratio, etiology of liver disease, presence of ascites, previous encephalopathy, serum albumin levels, serum bilirubin levels and coagulation parameters, international normalized ratio and platelet count. The mean Pugh score was significantly higher in group 1 ( 7.7 versus $6.2 ; \mathrm{P}<0.05$ ). The types of abdominal surgery (nephrectomy, gastrectomy, colectomy, small-bowel resection and duodenopancreatectomy) and the indications for surgery were similar in groups 1 and 2 (Table 2). The TIPS procedure was performed prophylactically in 13 patients; in five others, it was placed for variceal bleeding or gastric antral vascular ectasiarelated bleeding that occurred before surgery.

The TIPS procedure was performed a mean $72 \pm 21$ days before surgery in group 1 patients. The procedure was successful in all patients without any complications. The mean portal pressure gradient decreased from $21.4 \pm 3.9 \mathrm{mmHg}$ to $8.4 \pm 3.4 \mathrm{mmHg}$. 
TABLE 3

Postoperative complications

\begin{tabular}{lcc}
\hline Complication & Group $\mathbf{1}(\mathbf{n}=\mathbf{1 8})$ & Group $\mathbf{2}$ (n=17) \\
\hline Encephalopathy & 4 & 5 \\
Liver failure & 3 & 3 \\
Acute respiratory distress syndrome & 2 & 1 \\
Abdominal abscess & 1 & 3 \\
Ascites infection & 1 & 1 \\
Ascites leak & 2 & 0 \\
Pancreatic leak & 0 & 2 \\
Anastomotic leak & 0 & 1 \\
\hline
\end{tabular}

TABLE 4

Cause of death

\begin{tabular}{lcc}
\hline Cause & Group $\mathbf{1}(\mathbf{n}=\mathbf{1 8})$ & Group 2 $\mathbf{( n = 1 7 )}$ \\
\hline Acute respiratory distress syndrome & 1 & 1 \\
Multiorgan failure & 1 & 1 \\
Sepsis & 2 & 2 \\
Metastatic cancer & 2 & 1 \\
Liver failure & 1 & 0 \\
Stroke & 1 & 0 \\
Massive hematuria & 0 & 1
\end{tabular}

The mean Pugh score was 7.4 before TIPS and remained stable immediately before abdominal surgery (7.7; P not significant).

Postoperative evolution is summarized in Table 3. Operative blood transfusions were required for six patients in group 1 and seven patients in group 2. A total of 17 blood units (range one to four per patient) were transfused in group 1 compared with 16 blood units (range two to four per patient) in group 2. The differences between mean hemoglobin levels measured before and $24 \mathrm{~h}$ after surgery were similar in both groups ( $7 \pm 19 \mathrm{~g} / \mathrm{L}$ versus $12 \pm 12 \mathrm{~g} / \mathrm{L}$; P not significant).

Encephalopathy was observed in four patients in group 1 and five patients in group 2. Liver failure followed surgery in three patients in each group. The incidence of miscellaneous complications was also similar and consisted of acute respiratory distress syndrome, abdominal abscess, peritoneal bleeding, peritonitis, ascites, pancreatic or anastomotic leak (Table 3). The length of hospital stay was 17.4 days in group 1 and 22.6 days in group 2 (P not significant).

Two patients from each group died within one month, eight patients and six patients died within one year. The causes of death are listed in Table 4. The cumulative survival rates were similiar in both groups at one month (83\% and $86 \%)$ and at one year (54\% and 62\%) (Figure 1). Multivariate analysis using the Cox proportional hazards model showed that neither the Pugh score nor the TIPS placement had an independent value for the prediction of survival (Table 5).

\section{DISCUSSION}

The present study suggested that preoperative portal decompression with TIPS did not improve the outcome after abdominal surgery in cirrhotic patients. This finding was disappointing and unexpected.

Abdominal surgery is associated with a high-risk of postoperative complications in cirrhotic patients and the survival

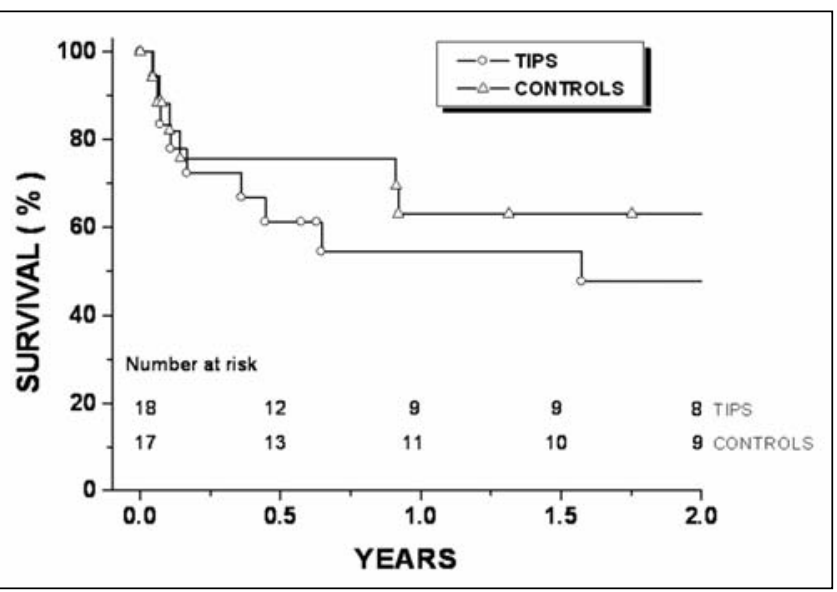

Figure 1) Cumulative proportion of cirrhotic patients surviving in group 1 (transjugular intrahepatic portosystemic shunt [TIPS] group) and group 2 (control group)

TABLE 5

Factors predicting survival

\begin{tabular}{llclllc}
\hline & \multicolumn{2}{c}{ Univariate analysis } & & \multicolumn{2}{c}{ Multivariate analysis } \\
\cline { 2 - 3 } \cline { 6 - 7 } Variable & $\begin{array}{c}\text { Hazard ratio } \\
\text { median (range) }\end{array}$ & $\mathbf{P}$ & & $\begin{array}{c}\text { Hazard ratio } \\
\text { median (range) }\end{array}$ & $\mathbf{P}$ \\
\hline Preoperative TIPS & $1.91(0.70-5.18)$ & 0.20 & & $1.39(0.42-4.61)$ & 0.58 \\
Pugh score $>7$ & $2.07(0.77-5.6)$ & 0.15 & & $1.72(0.52-5.70)$ & 0.37 \\
\hline
\end{tabular}

TIPS Transjugular intrahepatic portosystemic shunt

rate is markedly lower than in noncirrhotic patients. The prognosis is influenced by the degree of portal hypertension and, probably most importantly, by the severity of liver failure $(1-3,7,8)$.

TIPS is a nonsurgical modality used to decrease portal pressure. It is a safe procedure considered to be minimally invasive and it can be done even in patients with advanced liver cirrhosis (4). It appears logical to assume that preoperative portal decompression following TIPS placement would facilitate abdominal surgery, decrease operative bleeding and postoperative ascites; possibly improving the postoperative outcome. This approach has been evaluated in several case reports $(9,10)$ with promising results.

In a recent uncontrolled series (5), seven cirrhotic patients with portal hypertension underwent extrahepatic abdominal operations with preoperative TIPS placement; intraoperative transfusions were needed in only two patients and only one patient died within one month. Accordingly, it was suggested that decompression of the portal venous system by TIPS may be useful to decrease the operative risk of major abdominal surgery in cirrhotic patients with portal hypertension.

The discrepancy between the results reported in this paper and the present study may be explained by differences in methodology and also in patient population.

The Azoulay et al (5) study was prospective, but there was no control group. We compared the outcome of the study group who underwent preoperative TIPS placement with a control group matched for age, etiology of liver disease, indications for surgery and coagulation parameters. Although our trial was not randomized, the results suggested 
that preoperative TIPS placement did not improve postoperative outcomes in our patient population.

However, our conclusions may have been biased by two potentially confounding variables. The TIPS group was sicker than the control group, as shown by a slightly higher Pugh score. However, a multivariate analysis demonstrated that the results were similar after adjusting for this variable. The portohepatic gradient was not measured in all patients of the control group. It is possible that portal hypertension was less severe in these patients, which could explain the better postoperative outcome than reported previously. However, evidence of portal hypertension, such as splenomegaly, ascites, low platelets, esophageal varices and intra-abdominal collateral circulation, was demonstrated in 14 of 17 patients in the control group. Removal of the three patients without evidence of portal hypertension from the analysis did not change the results in terms of operative bleeding, postoperative complications or survival.

The absence of beneficial effects of preoperative TIPS placement on postoperative outcomes could be due to improved management of cirrhotic patients with portal hypertension before, during and after surgery; progress has been made in hematological preparation, anesthetic methods, postoperative hemodynamic monitoring and prevention of

\section{REFERENCES}

1. Aranha GV, Greenlee HB. Intra-abdominal surgery in patients with advanced cirrhosis. Arch Surg 1986;121:275-7.

2. del Olmo JA, Flor-Lorente B, Flor-Civera B, et al. Risk factors for nonhepatic surgery in patients with cirrhosis. World J Surg 2003;27:647-52.

3. Zarski JP, Richard P, Bourbon P, Demongeot J, Rahail M. Extrahepatic digestive surgery in cirrhotic patients: Mortality, morbidity, preoperative prognostic factors. Gastroenterol Clin Biol 1988;12:43-7.

4. Boyer TD. Transjugular intrahepatic portosystemic shunt: Current status. Gastroenterology 2003;124:1700-10.

5. Azoulay D, Buabse F, Damiano I, et al. Neoadjuvant transjugular intrahepatic portosystemic shunt: A solution for extrahepatic abdominal operation in cirrhotic patients with severe portal hypertension. J Am Coll Surg 2001;193:46-51.

6. Pomier-Layrargues G, Villeneuve JP, Deschenes M, et al. Transjugular intrahepatic portosystemic shunt (TIPS) versus endoscopic variceal ligation in the prevention of variceal rebleeding in patients with cirrhosis: A randomised trial. Gut 2001;48:390-6. infections; in addition, surgeons have also gained much experience with this type of operation over the years.

On the other hand, TIPS may have deleterious effects in some patients, namely, the onset of high cardiac output failure (11), liver failure and hepatic encephalopathy (4). These complications may counterbalance the beneficial effects of TIPS related to the relief of portal hypertension. In the TIPS group, one patient died from progressive liver failure and two from acute respiratory distress syndrome potentially induced or precipitated by the TIPS procedure. In addition, one patient developed extensive lung metastases from colon cancer, probably due to direct access of neoplastic cells to the lungs through the TIPS.

\section{CONCLUSION}

The present study suggests that preoperative TIPS placement does not improve the outcome of cirrhotic patients after elective extrahepatic abdominal surgery and cannot be recommended in clinical practice. However, this is a retrospective, comparative study, and most patients had minimal or moderate liver failure. A beneficial effect in patients with more severe portal hypertension or liver failure cannot be excluded. The exact value of this approach must be evaluated in the future by prospective, randomized clinical trials.

7. Metcalf AMT, Dozois RR, Wolff BG, Beart RW Jr. The surgical risk of colectomy in patients with cirrhosis. Dis Colon Rectum 1987;30:529-31.

8. Mansour A, Watson W, Shayani V, Pickelman J. Abdominal operations in patients with cirrhosis: Still a major surgical challenge. Surgery 1997;122:730-5.

9. Grubel P, Pratt DS, Elhelw T. Transjugular intrahepatic portosystemic shunt for portal decompression before abdominal or retroperitoneal surgery in patients with severe portal hypertension. J Clin Gastroenterol 2002;34:489-90.

10. Norton SA, Vickers J, Callaway MP, Alderson D. The role of preoperative TIPSS to facilitate curative gastric surgery. Cardiovasc Intervent Radiol 2003;26:398-9.

11. Merli M, Valeriano MM, Funaro V, et al. Modifications of cardiac function in cirrhotic patients treated with transjugular intrahepatic portosystemic shunt (TIPS). Am J Gastroenterol 2002;97:142-8 


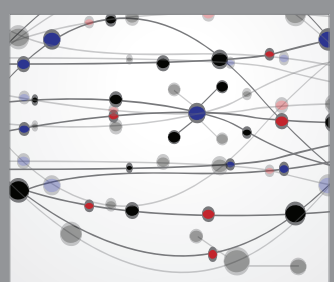

The Scientific World Journal
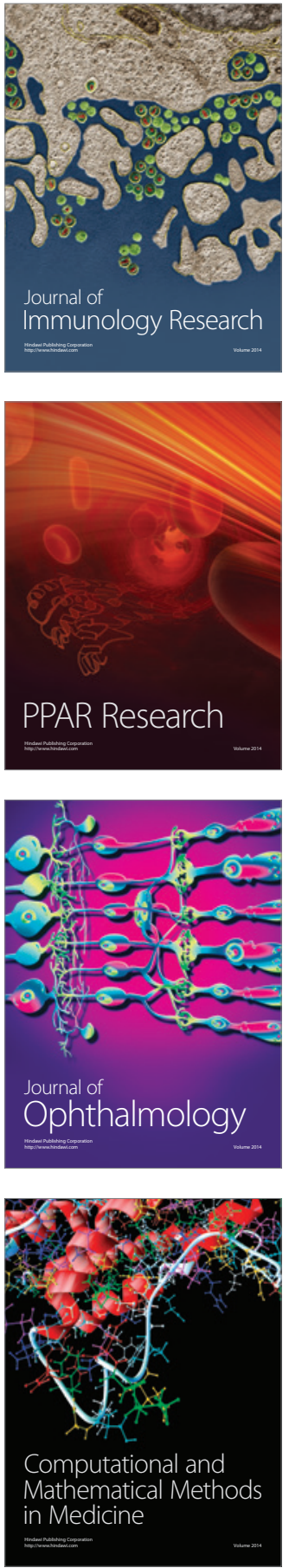

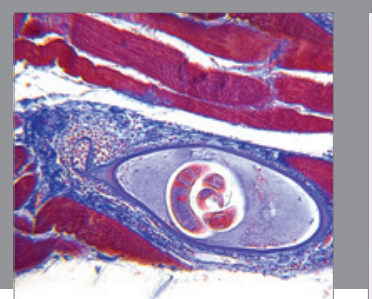

Gastroenterology Research and Practice

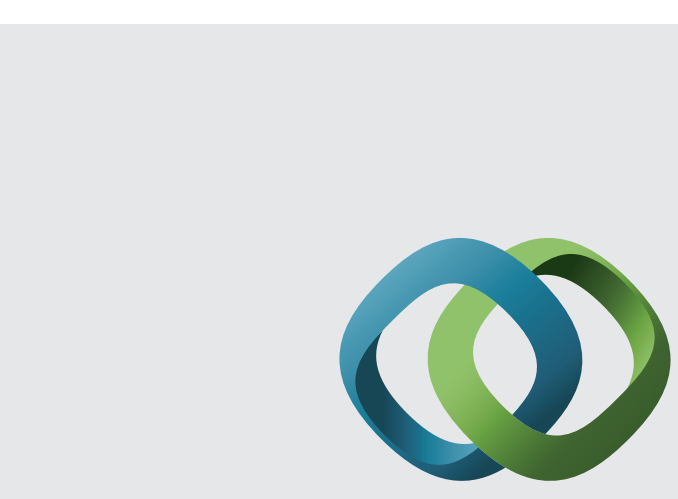

\section{Hindawi}

Submit your manuscripts at

http://www.hindawi.com
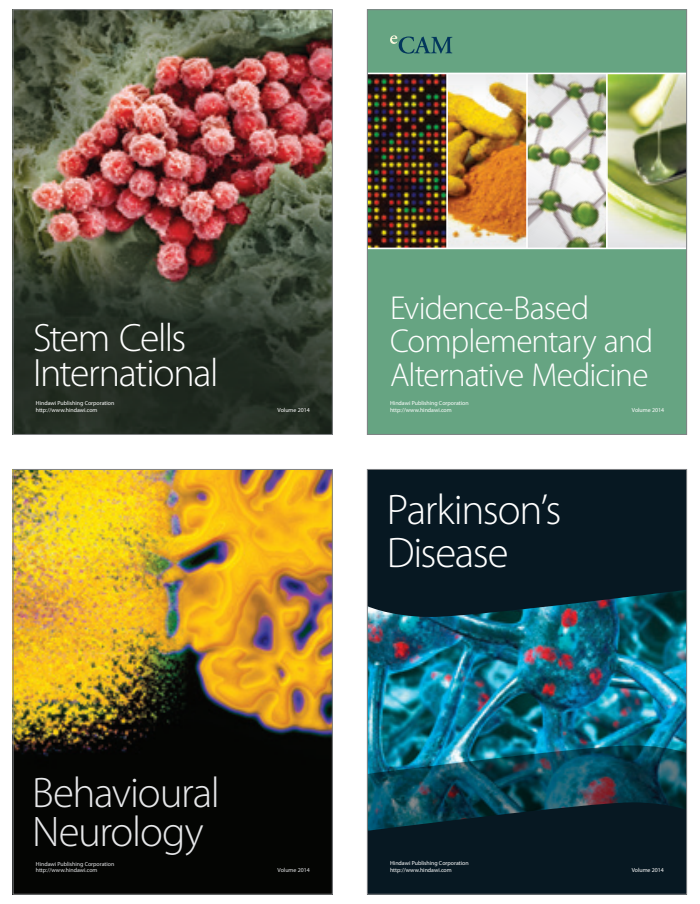
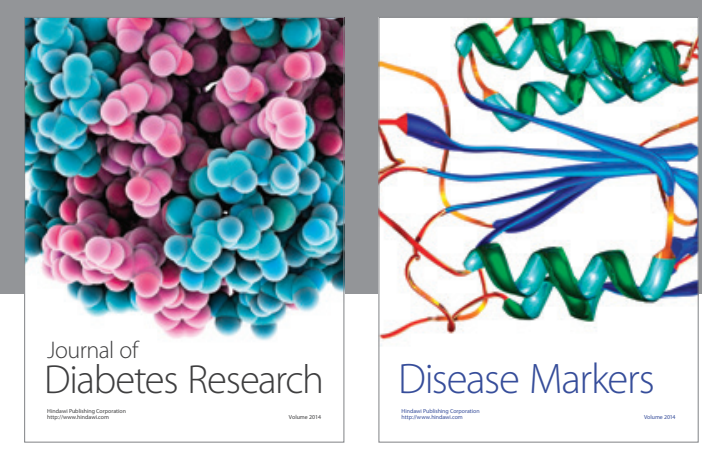

Disease Markers
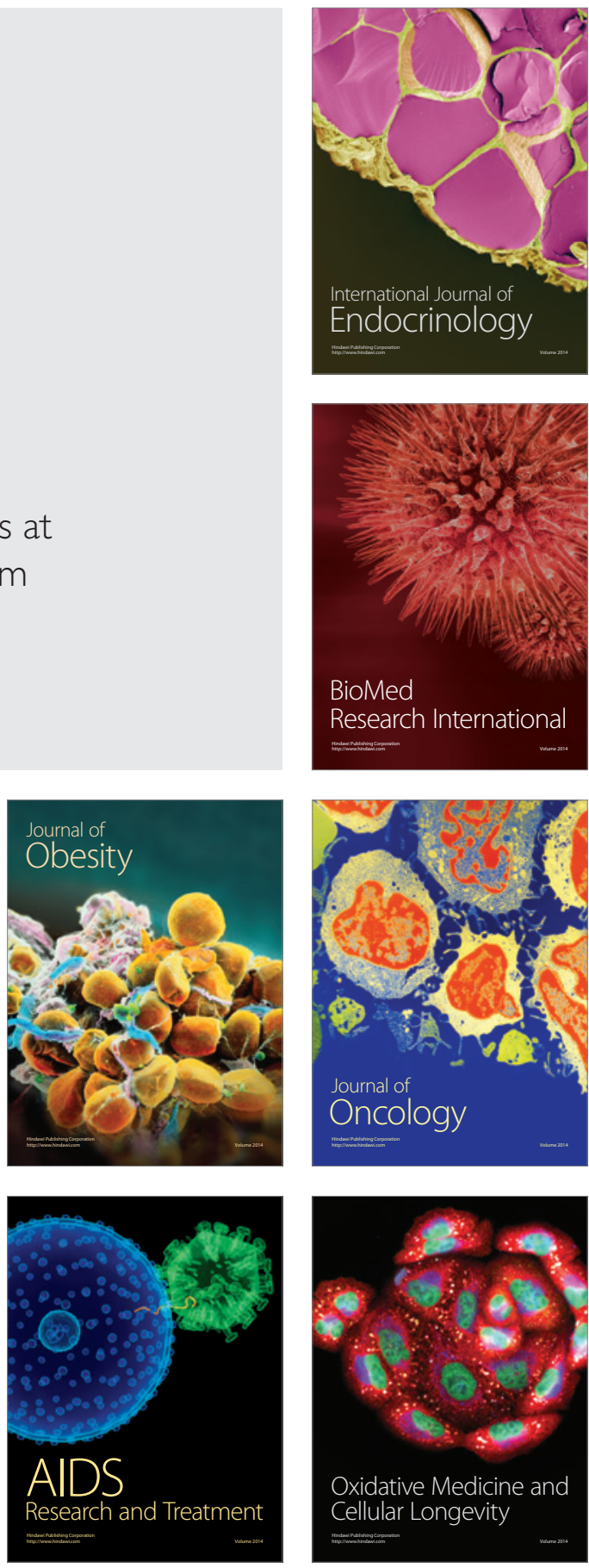